\title{
Agency and Body Ownership in Immersive Virtual Reality Environments: A Laboratory Study
}

\author{
Henrik Freude \\ University of Siegen \\ hernik.freude@uni-siegen.de
}

\author{
Caroline Reßing \\ University of Siegen \\ caroline.ressing@uni-siegen.de
}

\author{
Michael Knop \\ University of Siegen \\ michael.knop@uni-siegen.de
}

\author{
Marius Mueller \\ University of Siegen \\ marius.mueller@uni-siegen.de
}

\author{
Bjoern Niehaves \\ University of Siegen \\ bjoern.niehaves@uni-siegen.de
}

\begin{abstract}
Virtual reality (VR) technologies such as head-mounted displays are gaining increasing attention since the Oculus Rift development kit entered the market in 2016. VR is assumed to offer great potential for different purposes such as entertainment, gaming, education, or healthcare. VR provides an enclosed virtual environment in which users can become immersed, can move and look freely at 360degree in any direction, and they can interact, manipulate, or create virtual objects with their entire body. With regard to these properties and the characteristic of immersion, we examine how immersion can be enhanced by the theoretical constructs of agency and body ownership in a VR space. Therefore, we investigate the perception of agency and the sense of body ownership with 69 participants in a laboratory study with a self-developed $V R$ environment. We found a positive significant effect of agency but no effect of body ownership on immersion.
\end{abstract}

\section{Introduction}

Virtual reality (VR) technologies have gained much popularity since the market entrance of the Oculus Rift (development kit) in 2016 [14]. Recently, a couple of VR technologies such as Oculus Rift, HTC Vive, or PlayStation VR are available on the market [3]. One certain characteristic of VR is immersion which arises through the use of head-mounted displays (HMDs) and the restriction of what a user can see [5]. VR systems were primarily developed for hedonic purposes but, nowadays, they are used for several contexts [20]. For instance, games and films are produced for VR environments which allow their audience to dive into a 360-degree experience. More serious examples recently refer to education or healthcare [e.g. 33, 36, $39,56,59]$.

Immersive VR systems are computer-generated, three-dimensional, and interactive scenarios in which people become immersed [61]. Applications in VR environments depend on the degree of immersion due to its simulation of a completely enclosing virtual space [34]. Here, VR is distinguished into immersive and non-immersive VR. Non-immersive VR systems, in contrast to immersive VR, often refer to laptops or desktop computers [57]. The use of VR-HMDs are related to single user experiences [43] and are typically limited to single user sessions of 30 minutes [37]. For example, current research on low and high immersive conditions of online shopping have shown that users learn more about provided products with regard to knowledge and attitude in the high condition than in the low one [57]. Another study found similar results and has investigated product presentation formats and task complexity within virtual product experiences and consumers' product understanding [19].

Besides HMDs, recent VR technologies provide their users controllers to interact with virtual objects [46]. Users can be active rather than just passively observing contents because they can interact, create, or manipulate different things within a virtual space with their entire body [25, 33]. A virtual space enables users a precise interaction and a high degree of visualization of objects and processes which otherwise are not possible or infeasible to depict in the real world [51]. Moreover, higher precision and visualization allow for a more intense, focused experience and to conduct certain tasks [23, 24, 33].

In literature, VR gains increasing attention and the number of studies continuously rise [33, 39, 49]. With regards to educational or healthcare applications, VR enables people to be motivated and be engaged in certain tasks through gamification elements [59]. 
Further, it allows to make abstract settings more tangible such as geometrical mathematics, which can be more easily understood than in traditional paper and pencil settings [18]. As mentioned above, in VR users can be active rather than passively observing. Müns et al. have investigated medical trainings with regard to surgery and found that active interactions are helpful for students, ideally combined with haptic feedback [36]. The same holds true for VR simulations of an entire operating room and the opportunity to interact and discuss together [35]. Moreover, VR enables its users to visit or to show aspects, places, or objects of interest, which are practically infeasible in reality. For instance, a class of students can virtually visit historical places in a short period of time such as Stonehenge and Niagara Falls at the same day [29] or a human heart can be virtually visualized for educational [7, 35] or therapeutical purposes [26]. In accordance with Slater and Sanchez-Vives, a fourth advantage of VR is the possibility to break the bounds of reality in sense of exploration. The rules of physics can be manipulated to change gravity, to make the speed of light visible, or to explore biological cell utilizing [27].

A key element of VR, as mentioned before, is the central characteristic immersion. Immersion is defined as an individual's perception of total engagement in a particular task or interaction while other attentional demands from the external environment are ignored [1, 6]. In accordance with the literature, immersion is a central component of the theoretical approach of cognitive absorption, which is defined as a user's state of deep involvement with an information technology $[1,2]$. So far, research on immersion and on cognitive absorption, for instance, focusses on acceptance such nurses' e-learning acceptance [8], interactivity processes, imagery, and spatial presence and their impact on online learning environments [41, 42], hedonic motivation systems $[17,31]$, or actual learning and its explanatory variables $[15,28,32]$.

However, only sparse research focusses on empirical investigations especially on cause-effect relationships of how the sense of immersion can be enhanced within VR environments. First approaches argue for the essential construct of presence [24, 50, $51,52]$, state the importance of embodiment, presence, and social presence in virtual multi-user domains within a literature review [43], or qualitatively derive antecedents of immersion such as control, enjoyment, curiosity, or embodiment [23]. Nevertheless, these studies do only scarcely focus on the central aspects of how interactions with one's own hands take place (by use of provided controllers of HMDs such as Oculus Rift and HTC Vive) and how the use of one's entire body and the own perception of interactions influence the sense of immersion within a VR environment.
Literature refers to these phenomena as embodiment $[23,43,58]$. Embodiment is defined as practices of the body which can manifest as physical, i.e. sitting, gesturing, or touching objects and people, or as social, i.e. wearing appropriate fashionable clothes [58]. However, we argue that this definition is not differentiated enough because it refers mainly to virtual communities, which are reachable by non-immersive technologies. The psychological literature distinguishes embodiment into agency and body ownership [53]. Slater integrates the concepts of agency, i.e. the sense of being in voluntary control of action, and body ownership, i.e. the sense of the virtual body as one's own one [51]. As a consequence, we refer the theoretical construct agency to the use of provided controllers of current VR-HMDs and their possibility to interact, create, or manipulate virtual objects. Furthermore, we relate the construct body ownership to the kind of with what users are interacting in a virtual space, notably to the visual aspects of what they see during their interaction such as hands or the controller. So far, to the best of our knowledge no research approach is known that links agency and body ownership within a VR environment to enhance the sense of immersion. Consequently, we refer to the definitions of immersion [1], the argumentation of Burton-Jones and Straub that immersion is the central construct of cognitive absorption because it is the only one which measures absorption or immersion [6], and to the definitions of agency and body ownership [51, 53]. We consider this missing linkage between immersion, agency, and body ownership as a research gap within VR environments.

In order to investigate agency and body ownership and how these can enhance the sense of immersion in a VR environment, this work is structured as follows. First, we present the theoretical background on these three theoretical constructs. Second, we derive our hypotheses, and third, we describe our laboratory study. Subsequently, we analyze our data and present our results. Finally, we conclude our paper with a discussion of implications, limitations, and future research.

\section{Theoretical Background and Hypotheses}

To develop a better understanding of how the sense of immersion within VR environments can be increased for different purposes such as education, entertainment, or healthcare, we integrate agency and body ownership as predictors for immersion. Furthermore, we argue that agency will be represented by the use of VR-HMD related controllers such as HTC Vive or Oculus Rift. Body ownership will be 
manipulated within the meta design in order to enhance the sense of the virtual body so it is perceived as one's own. The research model is depicted in Figure 1.

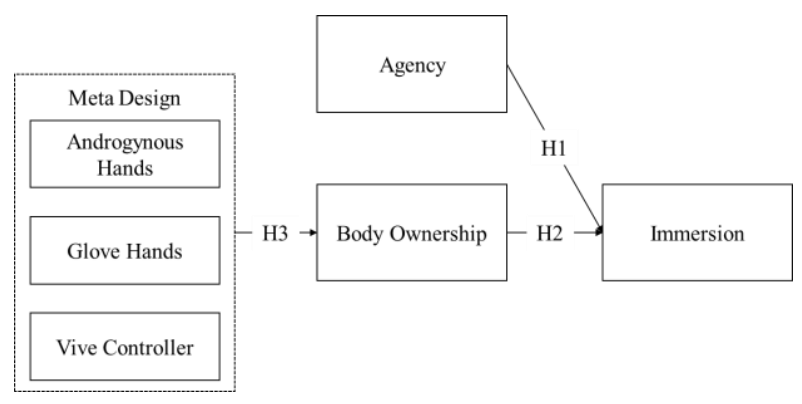

Figure 1. Research Model

Immersion. Immersion is a central characteristic of VR technologies such as VR-HMDs [23, 24, 30, 33]. Yet, immersion as part of the theoretical approaches of flow theory and cognitive absorption was mainly investigated within educational settings, focusing on the actual learning [e.g. 15, 24, 28, 32] or on acceptance research [e.g. 1, 8, 16, 31, 40, 41, 42]. Overall, the concept of immersion deals with a mental state of absorption, a feeling of engagement, including intense concentration, a sense of being in control, a loss of self-consciousness, and a different perception of time [1, 2]. In literature, immersion is referred to within the context of individual technology use behavior as a multi-dimensional construct [e.g. 60] or as a uni-dimensional central component [e.g. 6, 38]. Both views have in common that flow or absorption and, thus, immersion shape individual attitudes and behavior towards information technology. These, for instance, arise through the key component of intrinsic motivation because an individual behaves in their own interest to derive pleasure and satisfaction from an activity [9].

Agency and Body Ownership. Central characteristics of VR environments that provide its users VR-HMD controllers are the possibility to be active rather than just passively observing contents, to perform tasks, or to create and manipulate virtual objects [46]. These characteristics allow users to precisely act in a virtual environment as in the real world. So far, recent literature refers this phenomenon of controlling elements such as the virtual body within a VR environment to embodiment [43]. Here, we would further argue to extend this understanding and distinguish embodiment from agency and body ownership. Slater and Sanchez-Vives state and differentiate embodiment into these both constructs in order to conceptual investigate both in the context of immersive VR learning environments [51]. As a consequence, we refer to agency as the sense of a user being in voluntary control of actions within a VR environment. From a first-person perspective in a VR space, the synchronous movement of a virtual hand can result in a higher sense of agency [4]. Current research in Information Systems (IS) often refers to a similar but not necessarily equal theoretical construct of interactivity [25]. Steuer defines interactivity as a user's opportunity to modify the form or content of a mediated environment [55]. However, most of this research is linked to non-immersive systems such as websites [e.g. 19, 48, 54]. Therefore, we argue that agency and its relation to embodiment is a more reliable construct for our purpose because it is already related to VR technologies and has already been at the core of empirical studies [e.g. 21, 22, 23, 51].

Following the description of the characteristics of VR environments above, the central component of immersion, i.e. a user's state of deep involvement with a technology, and the properties and definition of agency, we assume a positive relationship between agency and immersion. If users are in control of the action they perform within a virtual space, they will be more engaged in this virtual space and perceive it similar to the real world. Hence, we state our first hypothesis:

H1: The sense of agency will positively influence immersion within a VR environment.

Research on body ownership is mainly done within psychology and focuses on examinations with regard to full body perceptions in VR, moving rubber hand illusions, or presence questions [10, 21, 22, 50, 53]. Overall, the idea of body ownership refers to users who are in a virtual space, looking down at themselves, and noticing a virtual body substituting their own. This virtual body would be life sized, approximately occupy the same space as the real body [53]. Seeing the virtual body from a first person perspective already leads to the sense of a person's actual body. This illusion can be enhanced by further multisensory feedback such as the control of using one's own hands [4, 51]. In our case we are arguing in accordance with Taylor as well as Kalckert and Ehrsson who describe that if the visibility and interactions of the virtual body are in common, such as gestures like opening and closing hands, it will strengthen the feeling of body ownership $[21,22,58]$. Furthermore, we assume these aspects as a predictor for immersion because if users are interacting with human looking hands, they will perceive the virtual space as more natural and closer to the real world than with non-human looking hands. In order to determine human and non-human looking hands, we integrate results of prior research. We refer to studies with regard to presence and possible designs as long as these have shown significant results $[24,45]$. Schwind 
et al. have identified different depictions of hands within a virtual environment which show a good tradeoff between likeability, eeriness, and presence with regard to gender aspects [45]. They found that designs are still challenging but androgynous looking hands are a good compromise concerning gender. In accordance with Kampling who conducted an explorative study on VR, we argue that glove hands are an additional good compromise between human und less human looking hands [23]. We assume these to be sensed more as one's own body in VR than non-human looking VR controllers. As a consequence, we hypothesize:

H2: The sense of body ownership will positively influence immersion within a VR environment.

H3: More human looking hands while interacting in a VR environment will have a stronger impact on immersion than non-human looking hands.

\section{Research Method}

Design and Participants. In order to test the proposed hypotheses, we conducted a laboratory study (between-subject design) in a VR lab. We used a HTC Vive VR-HMD which provides HTC Vive controllers for interacting within the virtual environment. The study was conducted in a self-developed VR environment that was implemented in the Unreal Engine 4. This self-developed environment provided each participant a virtual post office, in which a virtual post process has to be completed. The virtual room consists of a typical post office equipment such as tables, chairs, and computers (c.f. Figure 2). At the beginning, each participant started in front of a counter on which a measure of scale, length, and an info sheet was placed. The info sheet has shown information on letters and parcels (weight, length, width, and price). Overall, we collected 69 observations and each participant took part in the study for 10 minutes. The majority of the sample was male (48 males, 21 females) with an average age $\mathrm{M}=23.79$ ( $\mathrm{SD}=3.13$ ). Most participants stated their profession as student $(85.5 \%)$.

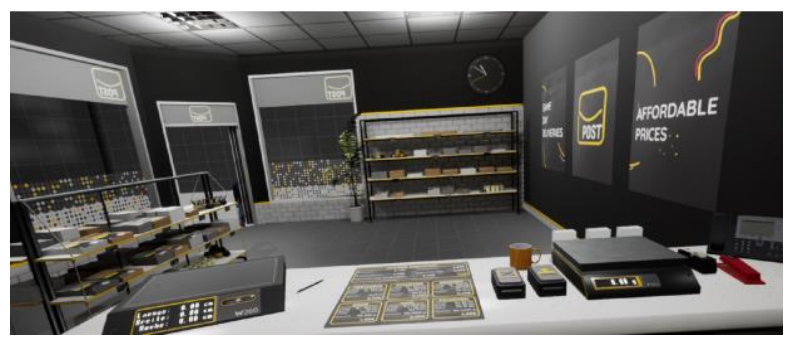

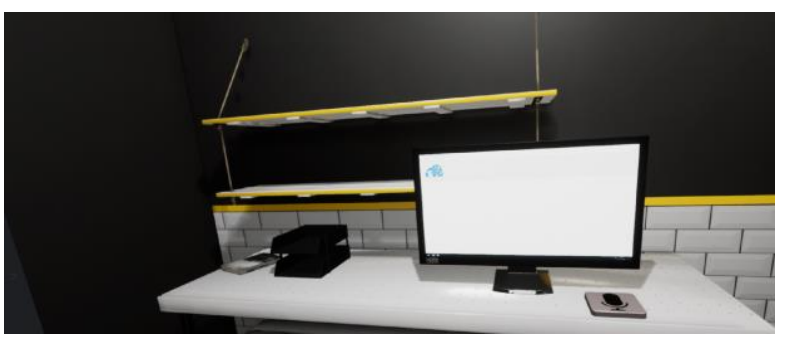

Figure 2. Virtual Environment

Procedure. The laboratory study followed a repeating procedure for each participant. At the beginning, each participant was welcomed by the experimenter, helped adjusting the VR-HMD and the controllers, and was explained the entire procedure of conducting a post process. Moreover, the experimenter observed the entire process to make sure that no participant bumps into objects. Overall, the aim of the study was to perform a step-by-step post process, which is repetitive and highly standardized but differs in certain details. The process starts with a virtual customer entering the room who hands over a letter or parcel. The participant has to weigh and measure it and assign it to a box in accordance with information on the info sheet. The box is composed of six different options: postcard, standard letter, compact, large package, or miscellaneous package. The participants receive visual (green/red lights) and auditory feedback to continue or to repeat the steps in order to do it correctly. Subsequently, they have to fill in a price into an appearing entry screen, in accordance with the info sheet, from which the participants receive feedback again. The entry screen for the price appears on the right side of the participants in order to not distract them during prior steps. After the participants have asked for the right price, the virtual customer leaves the post office and a new one with a new parcel or letter comes in. Here, we follow the idea that each participant has to perform repetitive but differing requests, which are interactive with virtual objects by using the controllers. They can interact with their entire body, using their hands to interact, create, or manipulate virtual objects. After completing the VR simulation, each participant was guided to another room to take part in the survey featuring all measurement items, manipulation checks as well as control variables. After that, they were debriefed.

Measurements of Variables. In order to examine how the sense of immersion within VR spaces can be increased, the participants used HTC Vive controllers for the perception of agency and different VR designs for body ownership were presented while interacting in the virtual space (c.f. Figure 3). The picture at the top shows androgynous human looking hands, the middle 
one glove looking hands, and the bottom one the control conditions with HTC Vive controllers. The first both conditions were tested with 24 participants each and the control condition with 21 participants (overall 69 participants).

All variables were measured on 7-point Likert scales (and were pre-tested with 6 participants), except the manipulation check (which was measured as a dummy variable). The used measurement items for immersion were adapted from literature [1, 6]. Agency and body ownership as well as the corresponding controls were adapted from Kalckert and Ehrsson [21, 22]. Agency control as well as body ownership control are used as a corrective measure of the actual measured variables agency and body ownership. The measurements are presented in Table 1.

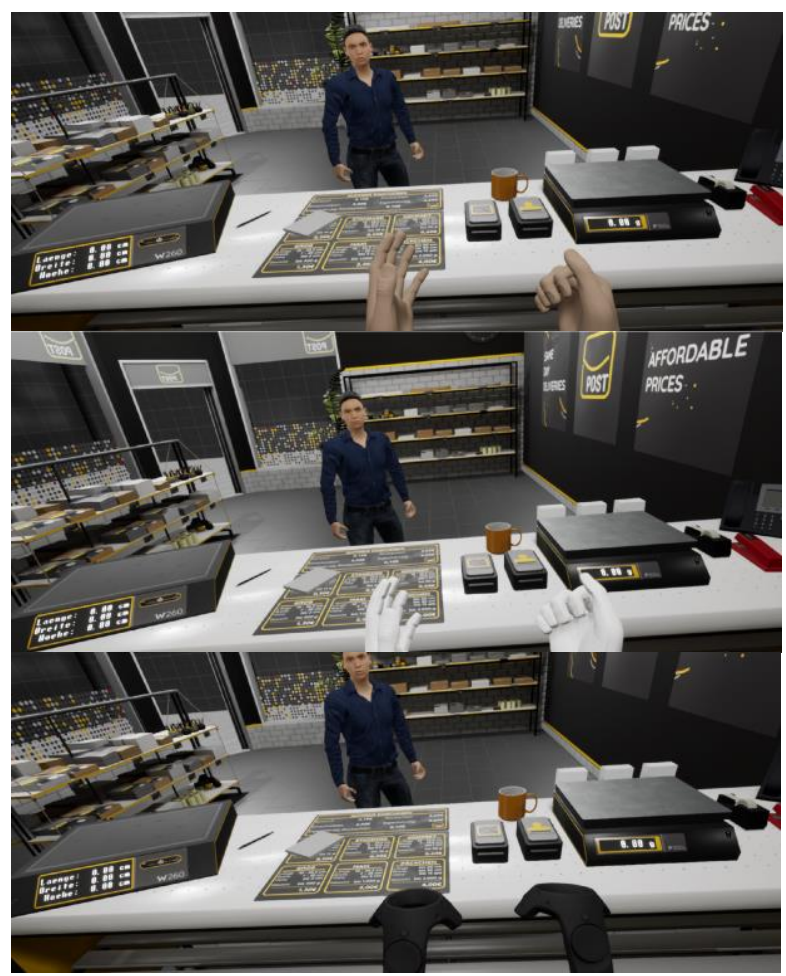

Figure 3. Design Options

\begin{tabular}{ll}
\hline Construct & Measurement Item \\
\hline & $\begin{array}{l}\text { While using the learning application } \\
\text { I was able to block out most other } \\
\text { distractions. }\end{array}$ \\
\cline { 2 - 2 } $\begin{array}{l}\text { Immersion } \\
\text { (adapted from }\end{array}$ & $\begin{array}{l}\text { I was using the learning application, } \\
\text { Agarwal and }\end{array}$ \\
\cline { 2 - 2 } $\begin{array}{l}\text { Karahanna } \\
\text { [1]) }\end{array}$ & $\begin{array}{l}\text { While using the learning application, } \\
\text { I was immersed in the task I was } \\
\text { performing. }\end{array}$ \\
\cline { 2 - 2 } & $\begin{array}{l}\text { When using the learning application, } \\
\text { I got distracted by other attentions } \\
\text { very easily. (rev) }\end{array}$ \\
\hline
\end{tabular}

\begin{tabular}{|c|c|}
\hline & $\begin{array}{l}\text { When using the learning application, } \\
\text { my attention has not got diverted } \\
\text { very easily. }\end{array}$ \\
\hline \multirow{3}{*}{$\begin{array}{l}\text { Body } \\
\text { ownership } \\
\text { (adapted from } \\
\text { Kalckert and } \\
\text { Ehrsson [3]) }\end{array}$} & $\begin{array}{l}\text { I felt as if I was looking at my own } \\
\text { hands. }\end{array}$ \\
\hline & $\begin{array}{l}\text { I felt as if the virtual hands were part } \\
\text { of my body. }\end{array}$ \\
\hline & $\begin{array}{l}\text { I felt as if the virtual hands were my } \\
\text { hands. }\end{array}$ \\
\hline \multirow{3}{*}{$\begin{array}{l}\text { Body } \\
\text { ownership } \\
\text { control } \\
\text { (adapted from } \\
\text { Kalckert and } \\
\text { Ehrsson [3]) }\end{array}$} & $\begin{array}{l}\text { It seems as if I had more than two } \\
\text { hands. }\end{array}$ \\
\hline & $\begin{array}{l}\text { It felt as if I had no longer hands, as } \\
\text { if my hands had } \\
\text { disappeared. }\end{array}$ \\
\hline & $\begin{array}{l}\text { I felt as if my real hands were } \\
\text { turning virtual. }\end{array}$ \\
\hline \multirow{3}{*}{$\begin{array}{l}\text { Agency } \\
\text { (adapted from } \\
\text { Kalckert and } \\
\text { Ehrsson [3]) }\end{array}$} & $\begin{array}{l}\text { I felt as if I could cause movements } \\
\text { of the virtual hands. }\end{array}$ \\
\hline & $\begin{array}{l}\text { I felt as if I could control movements } \\
\text { of the virtual hands. }\end{array}$ \\
\hline & $\begin{array}{l}\text { The virtual hands were obeying my } \\
\text { will and I could make them move } \\
\text { just like I wanted it. }\end{array}$ \\
\hline \multirow{3}{*}{$\begin{array}{l}\text { Agency } \\
\text { control } \\
\text { (adapted from } \\
\text { Kalckert and } \\
\text { Ehrsson [3]) }\end{array}$} & $\begin{array}{l}\text { I felt as if the virtual hands were } \\
\text { controlling my will. }\end{array}$ \\
\hline & $\begin{array}{l}\text { It seemed as if the virtual hands had } \\
\text { a will of their own. }\end{array}$ \\
\hline & $\begin{array}{l}\text { le virt } \\
\text { me. }\end{array}$ \\
\hline
\end{tabular}

Table 1. Measurement Items

\section{Data Analysis and Results}

Manipulation Check and Descriptive Statistics. As mentioned above, we included a manipulation check in order to control for our design choices and treatments. Here, we asked all participants if they had seen hands or a Vive controller within the virtual space. In order to test if the manipulation was successful we carried out a t-test about the randomly assigned manipulation (hands) and control (HTC Vive) conditions. The t-test presents no significant difference between the groups $(t=-0.4687, \quad d f=68, p=0.6407)$ which shows that our manipulation was successful because we tested if there is a difference the participants have not perceived our treatment, i.e. depiction of hands within the VR space. The descriptive statistics are displayed in Table 2.

Experimental Test. To test if the depiction of hands in a virtual space increases the perception of the own body, i.e. body ownership, we carried out an ANOVA to compare effects on the dependent factor variable. The analysis yields no significant result 
$(\mathrm{F}(2,68)=0.7736, \mathrm{p}=0.4655$ (over all three conditions: Vive controller $\mathrm{M}=3.59, \mathrm{SD}=2.07$, androgynous hands $\mathrm{M}=3.97, \mathrm{SD}=2.41$, and glove hands $\mathrm{M}=4.18$, $\mathrm{SD}=3.25)$ ). A further analysis of each treatment condition to the control conditions has also no significant effect (Vive controller vs. androgynous hands $\mathrm{F}(1,43)=0.7385, \mathrm{p}=0.3949$ and Vive controller vs. glove hands $\mathrm{F}(1,43)=1.4615, \mathrm{p}=0.2333)$. These results indicate no support for hypothesis $\mathrm{H} 3$.

\begin{tabular}{lc}
\hline Construct & Mean (Std.) of Constructs \\
\hline Immersion & $6.27(0.75)$ \\
Body Ownership & $3.93(1.59)$ \\
Body Ownership Control & $2.71(1.05)$ \\
Agency & $5.97(0.92)$ \\
Agency Control & $1.72(0.89)$ \\
\hline
\end{tabular}

Table 2. Descriptive Statistics

Regression Analysis. To test our hypotheses, we applied a regression analysis. The data suggest a statistically significant regression equation $(\mathrm{F}(2,68)=4.03, \mathrm{p}=0.0222)$ with a $\mathrm{R}^{2}=0.1593$. Hence, almost 16 percent of the variance can be explained through the independent variables. To test indicated hypotheses, our results indicate a statistically significant effect of agency on immersion $(\beta=0.21$, $\mathrm{p}=0.0425)$ but no significant effect of body ownership on immersion $(\beta=0.05, p=0.3874)$. As a consequence, $\mathrm{H} 1$ can be supported but not $\mathrm{H} 2$.

In order to check for control variables (age, gender, body ownership control, and agency control) we did not find any further significant effect (c.f. Table 3). We further conducted a t-test in order to control for differences between the variables agency and agency control $(\mathrm{t}=22.21, \mathrm{df}=68, \mathrm{p}=0.000)$ as well as body ownership and body ownership control $(\mathrm{t}=6.35, \mathrm{df}=68$, $\mathrm{p}=0.000)$. The results indicate significant differences.

\begin{tabular}{lc}
\hline Variable & $\boldsymbol{\beta}$ (p-value) \\
\hline Intercept & $4.77(0.00)$ \\
Body Ownership & $0.05(0.38)$ \\
Body Ownership Control & $0.05(0.59)$ \\
Agency & $0.21(0.04)$ \\
Agency Control & $-0.03(0.79)$ \\
Age & $0.01(0.63)$ \\
Gender & $-0.19(0.39)$ \\
\hline $\mathrm{R}^{\mathbf{2}}$ & 0.1593 \\
$\mathrm{~F}$ & $4.03(0.02)$ \\
\hline
\end{tabular}

Table 3. Regression Summary

\section{Discussion and Implications}

Discussion of Results. The theoretical constructs of agency and body ownership allow further insights with regard to research on immersive VR technologies.
This is why the study at hand seeks to extend prior research on the theoretical construct of immersion and how the sense of immersion can be enhanced in VR environments. Our work emphasizes embodiment and its further differentiations while considering certain characteristics of VR technologies such as HTC Vive.

Our results indicate interesting findings by supporting hypotheses $\mathrm{H} 1$ but not $\mathrm{H} 2$ and $\mathrm{H} 3$. In fact, agency positively influences immersion while using a VR technology such as HTC Vive $(\beta=.21, \mathrm{p}=.04)$. This finding suggests the importance of being in control of the interaction someone can perform within a VR environment to be more engaged with this environment, i.e. a higher immersion.

Although, we found that our manipulation check worked $(\mathrm{t}=-.4687, \mathrm{p}=.6407$; which means that participants who were in the treatment or control group have perceived it as the treatment, i.e. androgynous or white glove looking hands, or control condition, i.e. HTC Vive controller), we found no differences within the treatments (ANOVA results between groups: $\mathrm{F}(2,68)=.7736, \mathrm{p}=.4655)$. Moreover, we further found no support for the influence of body ownership on immersion $(\beta=.05, p=.38)$. In summary, we conclude that if the experimental conditions do not affect the sense of body ownership, body ownership does not influence immersion significantly. Therefore, we assume body ownership to be a more complex phenomenon within immersive and interactive VR environments. Here, it could be interesting to further explore phenomena with regard to haptic feedback while interacting. We assume our manipulation could have an effect on body ownership if the participants would have received haptic feedback to get a more realistic feeling while they interact with virtual objects.

Implications for Theory and Design. The study at hand contributes by several implications for theory and design of an immersive VR technology. Overall, current VR technologies using HMDs aim at different research fields in order to enhance learning outcomes [e.g. 24, 33, 39, 44, 53], for better entertainments [47], or to improve healthcare solutions [e.g. 7, 13, 26, 35, 36]. Our study argues for an integration of the theoretical constructs of agency and body ownership to explain immersion, i.e. a sense of being deeply involved with a technology [1]. We extend existing literature on agency $[4,21,22,51]$ by means of including characteristics of VR technologies such as the use of provided controllers. These controllers allow the users to interact, create, or manipulate objects in a virtual space in a way similar to the real world [33, 48]. We assume these characteristics and the opportunity to interact in a natural (real world alike) way can not only enhance immersion, it can also have positive effects on 
virtual learning environments such as implicit learning $[24,33,39,44]$ or healthcare outcomes such as surgery training and visualizations of human bodies [7, 26, 35, 36].

Our second implication aims at the experimental treatments of our conducted study. We have not found a significant relation on the design manipulations and suggest that each participant who took part used the Vive controllers to interact in the VR space, which, in turn, led to a weaker body self-perception. Current literature on body ownership [10,11, 21, 22] uses a much stronger treatment to investigate the sense of one's own body by the rubber hand illusion. We followed the assumption to strengthen the feeling of body ownership by a high synchronicity of the virtual and the real hand [53]. But for future research we suggest to include technological extensions that lead users to a higher perception of body ownership such as a Leap Motion technology or Manus VR gloves which allow to use one's own hands to interact in the VR space. For instance, a Leap Motion would sense the hand of a user by a camera or a Manus VR glove uses integrated sensors within the glove to trigger finger and hand movements. Moreover, we suppose in accordance with existing literature [43, 44, 46, 51], the perception of the virtual body as the own one will be increased by the stronger feeling of naturalness.

\section{Concluding Remarks}

Given our contributions, our study has limitations. To test our design manipulations, we conducted a laboratory study with 69 participants. Yet, this sample size is relatively small which could have led to the so far low coefficient of determination $\left(\mathrm{R}^{2}\right)$. Moreover, as suggested above, our findings could show better results in case we used more body and natural related technologies where participants would use their own hands instead of may be perceived artificial controllers. We could build upon existing studies with regard to augmented reality that artificial arms are perceived as one own ones [12]. Here, for a future study we would integrate a control measurement to compare both technologies in order to investigate a possible of effect of a HMD controller versus a probably more natural technology. Future research could further investigate the already found positive effects of agency on immersion with regard to more natural technologies such as Manus VR gloves or a Leap Motion. For instance, recent research has already shown positive effects of a leap motion on presence [45] and we assume that future research can combine these findings with investigations on body ownership and agency.

\section{Acknowledgements}

This article is funded by the project ELISE and the German Federal Ministry of Education and Research (BMBF, No. 16SV7512).

\section{References}

[1] Agarwal, R., and E. Karahanna, "Time Flies When You're Having Fun: Cognitive Absorption and Beliefs about Information Technology Usage", MIS Quarterly 24(4), 2000, pp. 665 .

[2] Agarwal, R., V. Sambamurthy, and R.M. Stair, "Cognitive Absorption and the Adoption of New Information Technologies.", Academy of Management Proceedings 1997(1), 1997, pp. 293-297.

[3] Anthes, C., R.J. Garcia-Hernandez, M. Wiedemann, and D. Kranzlmuller, "State of the art of virtual reality technology", IEEE (2016), 1-19.

[4] Banakou, D., P.D. Hanumanthu, and M. Slater, "Virtual Embodiment of White People in a Black Virtual Body Leads to a Sustained Reduction in Their Implicit Racial Bias", Frontiers in Human Neuroscience 10, 2016, pp. 1-12.

[5] Biocca, F., "The Cyborg's Dilemma: Progressive Embodiment in Virtual Environments", Journal of Computer-Mediated Communication 3(2), 1997, pp. 1-18.

[6] Burton-Jones, A., and D.W. Straub, "Reconceptualizing System Usage: An Approach and Empirical Test", Information Systems Research 17(3), 2006, pp. 228-246.

[7] Chan, S., F. Conti, K. Salisbury, and N.H. Blevins, "Virtual Reality Simulation in Neurosurgery Technologies and Evolution", Neurosurgery 72(1), 2013, pp. A154-A164.

[8] Cheng, Y.-M., "Exploring the Roles of Interaction and Flow in Explaining Nurses' E-Learning Acceptance", Nurse Education Today 33(1), 2013, pp. 73-80.

[9] Csikszentmihalyi, M., Flow: the psychology of optimal experience, Harper \& Row, New York, 1990.

[10] Ehrsson, H.H., "The Concept of Body Ownership and Its Relation to Multisensory Integration", In The Handbook of Multisensory Processes. MIT Press, 2004, 775-792.

[11] Ehrsson, H.H., K. Wiech, N. Weiskopf, R.J. Dolan, and R.E. Passingham, "Threatening a rubber hand that you feel is yours elicits a cortical anxiety response", Proceedings of the National Academy of Sciences 104(23), 2007, pp. 98289833. 
[12] Feuchtner, T., and J. Müller, "Extending the Body for Interaction with Reality", Proceedings of the 2017 CHI Conference on Human Factors in Computing Systems, ACM (2017), 5145-5157.

[13] Garrett, B., T. Taverner, D. Gromala, G. Tao, E. Cordingley, and C. Sun, "Virtual Reality Clinical Research: Promises and Challenges", JMIR Serious Games 6(4), 2018, pp. 1-10.

[14] Gleasure, R., and J. Feller, "A Rift in the Ground: Theorizing the Evolution of Anchor Values in Crowdfunding Communities through the Oculus Rift Case Study", Journal of the Association for Information Systems 17(10), 2016, pp. 708-736.

[15] Goel, L., N.A. Johnson, I. Junglas, and B. Ives, "How Cues of What can be done in a Virtual World Influence Learning: An Affordance Perspective", Information \& Management 50(5), 2013, pp. 197-206.

[16] Guo, Z., L. Xiao, C. Van Toorn, Y. Lai, and C. Seo, "Promoting Online Learners' Continuance Intention: An Integrated Flow Framework", Information \& Management 53(2), 2016, pp. 279-295.

[17] van der Heijden, H., "User Acceptance of Hedonic Information Systems", MIS Quarterly 28(4), 2004, pp. 695704.

[18] Hwang, W.-Y., and S.-S. Hu, "Analysis of Peer Learning Behaviors Using Multiple Representations in Virtual Reality and their Impact on Geometry Problem Solving”, Computers \& Education 62, 2013, pp. 308-319.

[19] Jiang, Z. (Jack), and I. Benbasat, "The Effects of Presentation Formats and Task Complexity on Online Consumers' Product Understanding”, MIS Quarterly 31(3), 2007, pp. 475-475.

[20] Jung, T., and M.C. tom Dieck, eds., Augmented Reality and Virtual Reality, Springer Berlin Heidelberg, New York, NY, 2017.

[21] Kalckert, A., and H.H. Ehrsson, "The moving rubber hand illusion revisited: Comparing movements and visuotactile stimulation to induce illusory ownership", Consciousness and Cognition 26, 2014, pp. 117-132.

[22] Kalckert, A., and H.H. Ehrsson, "The spatial distance rule in the moving and classical rubber hand illusions", Consciousness and Cognition 30, 2014, pp. 118-132.

[23] Kampling, H., "The Role of Immersive Virtual Reality in Individual Learning", Proceedings of the 51 st Hawaii International Conference on System Sciences, (2018), 13971406.
[24] Kampling, H., "Feeling Presence in Immersive Virtual Reality for Individual Learning", ICIS 2018 Proceedings, (2018), 1-9.

[25] Khalifa, M., and N. Shen, "System Design Effects on Social Presence and Telepresence in Virtual Communities", Twenty-fifth International Conference on Information Systems, (2004), 547-558.

[26] Kress, B., and M. Shin, "Diffractive and Holographic Optics As Optical Combiners in Head Mounted Displays", Proceedings of the 2013 ACM Conference on Pervasive and Ubiquitous Computing Adjunct Publication, ACM (2013), 1479-1482.

[27] Lartigue, J., T. Scoville, and M. Pham, "Promoting K-8 Learning using Oculus Rift: Employing Virtual Reality to Increase Learning Outcomes in Elementary Biology", Association for the Advancement of Computing in Education (AACE) (2014), 1100-1105.

[28] Leong, P., "Role of Social Presence and Cognitive Absorption in Online Learning Environments", Distance Education 32(1), 2011, pp. 5-28.

[29] Lin, H., M. Chen, G. Lu, et al., "Virtual Geographic Environments (VGEs): A New Generation of Geographic Analysis Tool", Earth-Science Reviews 126, 2013, pp. 7484.

[30] Liu, D., C. Dede, R. Huang, and J. Richards, Virtual, Augmented, and Mixed Realities in Education, Springer, 2017.

[31] Lowry, P.B., J.E. Gaskin, N.W. Twyman, B. Hammer, and T.L. Roberts, "Taking 'Fun and Games' Seriously: Proposing the Hedonic-Motivation System Adoption Model (HMSAM)", Journal of the Association for Information Systems 14(11), 2013, pp. 617-671.

[32] Magni, M., C. Paolino, R. Cappetta, and L. Proserpio, "Diving Too Deep: How Cognitive Absorption and Group Learning Behavior Affect Individual Learning", Academy of Management Learning \& Education 12(1), 2013, pp. 51-69.

[33] Martín-Gutiérrez, J., C.E. Mora, B. Añorbe-Díaz, and A. González-Marrero, "Virtual Technologies Trends in Education”, EURASIA Journal of Mathematics, Science and Technology Education 13(1), 2017, pp. 469-486.

[34] Mills, S., and J. Noyes, "Virtual Reality: An Overview of User-related Design Issues", Interacting with Computers(11), 1999, pp. 375-286.

[35] Mishra, S., "Hologram the future of medicine - From Star Wars to clinical imaging”, Indian Heart Journal 69(4), 2017, pp. 566-567. 
[36] Müns, A., J. Meixensberger, and D. Lindner, "Evaluation of a Novel Phantom-based Neurosurgical Training System", Surgical Neurology International 5, 2014, pp. 1-14.

[37] Nilsson, A., A.-S. Axelsson, I. Heldal, and R. Schroeder, "The Long-term Uses of Shared Virtual Environments: An Exploratory Study", In R. Schroeder, ed., The Social Life of Avatars. Springer London, 2002, 112-126.

[38] Novak, T.P., D.L. Hoffman, and Y.-F. Yung, "Measuring the Customer Experience in Online Environments: A Structural Modeling Approach", Marketing Science 19(1), 2000, pp. 22-42.

[39] Ott, M., and L. Freina, "A Literature Review on Immersive Virtual Reality in Education: State of the Art and Perspectives", Conference proceedings of »eLearning and Software for Education « (eLSE), (2015), 133-141.

[40] Rodriguez-Ardura, I., and F.J. Martinez-Lopez, "Another Look at 'Being There' Experiences in Digital Media: Exploring Connections of Telepresence with mental Imagery", Computers in Human Behavior 30, 2014, pp. 508518.

[41] Rodríguez-Ardura, I., and A. Meseguer-Artola, "ELearning Continuance: The Impact of Interactivity and the Mediating Role of Imagery, Presence and Flow", Information \& Management 53(4), 2016, pp. 504-516.

[42] Rodríguez-Ardura, I., and A. Meseguer-Artola, "Flow in E-Learning: What Drives It and Why It Matters", British Journal of Educational Technology 48(4), 2017, pp. 899915.

[43] Schultze, U., "Embodiment and Presence in Virtual Worlds: A Review", Journal of Information Technology 25(4), 2010, pp. 434-449.

[44] Schwarze, A., H. Kampling, O. Heger, and B. Niehaves, "Is Virtual Reality the Future of Learning? A Critical Reflection", Proceedings of the 52nd Hawaii International Conference on System Sciences, (2019), 1759-1768.

[45] Schwind, V., P. Knierim, C. Tasci, P. Franczak, N. Haas, and N. Henze, “'These Are Not My Hands!': Effect of Gender on the Perception of Avatar Hands in Virtual Reality", Proceedings of the 2017 CHI Conference on Human Factors in Computing Systems, (2017), 1577-1582.

[46] Seibert, J., and D.M. Shafer, "Control mapping in virtual reality: effects on spatial presence and controller naturalness", Virtual Reality 22(1), 2018, pp. 79-88.

[47] Sharma, A., P. Bajpai, S. Singh, and K. Khatter, "Virtual Reality: Blessings and Risk Assessment", Workig Paper, 2017, pp. 1-22.
[48] Shen, K.N., and M. Khalifa, "System Design Effects on Online Impulse Buying”, Internet Research 22(4), 2012, pp. 396-425.

[49] Silva, J.N.A., M. Southworth, C. Raptis, and J. Silva, "Emerging Applications of Virtual Reality in Cardiovascular Medicine", JACC: Basic to Translational Science 3(3), 2018, pp. $420-430$.

[50] Slater, M., "Place illusion and plausibility can lead to realistic behaviour in immersive virtual environments", Philosophical Transactions of the Royal Society B: Biological Sciences 364(1535), 2009, pp. 3549-3557.

[51] Slater, M., and M.V. Sanchez-Vives, "Enhancing Our Lives with Immersive Virtual Reality", Frontiers in Robotics and AI 3, 2016, pp. 1-47.

[52] Slater, M., M. Usoh, and Y. Chrysanthou, "The Influence of Dynamic Shadows on Presence in Immersie Virtual Environments", In Selected Papers of the Second Eurogrphaics Workshops on VE '95. Springer-Verlag, London, 1995, 8-21.

[53] Slater, S., "Implicit Learning Through Embodiment in Immersive Virtual Reality", In D. Liu, C. Dede, R. Huang and J. Richards, eds., Virtual, Augmented, and Mixed Realities in Education. Springer, 2017, 19-34.

[54] Steinmann, S., T. Kilian, and D. Brylla, "Experiencing Products Virtually: The Role of Vividness and Interactivity in Influencing Mental Imagery and User Reactions", Thirtyfifth International Conference on Information Systems, (2014), 1-20.

[55] Steuer, J., "Defining Virtual Reality: Dimensions Determining Telepresence", Journal of Communication 42(4), 1992, pp. 73-93.

[56] Stone, R.J., "Blending the Best of the Real with the best of the Virtual: Mixed Reality Case Studies in Healthcare and Defence", In T. Jung and M.C. tom Dieck, eds., Augmented Reality and Virtual Reality. Springer Berlin Heidelberg, New York, NY, 2017, 277-294.

[57] Suh, K.-S., and Y.E. Lee, "The Effects of Virtual Reality on Consumer Learning: An Empirical Investigation", MIS Quarterly 29(4), 2005, pp. 673-697.

[58] Taylor, T.L., "Living Digitally: Embodiment in Virtual Worlds", In R. Schroeder, ed., The Social Life of Avatars. Springer London, London, 2002, 40-62.

[59] Villagrasa, S., D. Fonseca, and J. Durán, “Teaching Case: Applying Gamification Techniques and Virtual Reality for Learning Building Engineering 3D Arts", Proceedings of the Second International Conference on Technological Ecosystems for Enhancing Multiculturality, ACM (2014), 171-177. 
[60] Webster, J., L.K. Trevino, and L. Ryan, "The

Dimensionality and Correlates of Flow in Human-Computer

Interactions", Computers in Human Behavior 9(4), 1993, pp.

411-426.
[61] Wexelblat, A., ed., Virtual Reality Applications and Explorations, Academic Press Professional, Inc., San Diego, CA, USA, 1993. 